\title{
Title: Design and Implementation of an X-ray Strain Measurement Capability Using a Rotating
}

\author{
Author(s): $\begin{aligned} & \text { Anode Machine } \\ & \text { J. A. Roberts, LANSCE-MLNSC } \\ & \text { M. A. M. Bourke, MST-5 } \\ & \text { P. Rangaswamy, LANSCE-MLNSC }\end{aligned}$
}

Submitted to:

DOE Office of Scientific and Technical Information (OSTI)

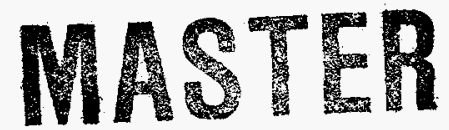

DETRABUTION OF THS DOCUMENT IS UNCMITED ph

\section{Los Alamos}

NATIONAL LABORATORY

Los Alamos National Laboratory, an affirmative action/equal oppontunity employer, is operated by the University of California for the U.S. Department of Energy under contract W-7405-ENG-36. By acceptance of this article, the publisher recognizes that the U.S. Government retains a nonexclusive, royaltyfree license to publish or reproduce the published form of this contribution, or to allow others to do so, for U.S. Government purposes. Los Alamos National Laboratory requests that the publisher identity this article as work performed under the auspices of the U.S. Department of Energy. Los Alamos National Laboratory strongly supports academic freedom and a researcher's right to publish; as an institution, however, the Laboratory does not endorse the viewpoint of a publication or guarantee its technical correctness. 


\section{DISCLAIMER}

This report was prepared as an account of work sponsored by an agency of the United States Government. Neither the United States Government nor any agency thereof, nor any of their employees, makes any warranty, express or implied, or assumes any legal liability or responsibility for the accuracy, completeness, or usefulness of any information, apparatus, product, or process disclosed, or represents that its use would not infringe privately owned rights. Reference herein to any specific commercial product, process, or service by trade name, trademark, manufacturer, or otherwise does not necessarily constitute or imply its endorsement, recommendation, or favoring by the United States Government or any agency thereof. The views and opinions of authors expressed herein do not necessarily state or reflect those of the United States Government or any agency thereof. 


\section{DISCLANIER}

Portions of this doecoment may be illegible in electronic image products. Images are produced from the best available original docomente 


\title{
Design and Implementation of an X-ray Strain Measurement Capability Using a Rotating Anode Machine
}

\author{
Joyce A. Roberts* and Partha Rangaswamy \\ Manuel Lujan, Jr. Neutron Scattering Center \\ Mark A. M. Bourke \\ Materials Science Technology Division
}

\begin{abstract}
This is the final report of a three-year, Laboratory Directed Research and Development (LDRD) project at the Los Alamos National Laboratory (LANL). Residual stresses close to the surface can improve the reliability and lifetime of parts for technological applications. X-ray diffraction plays a significant role in gaining an exact knowledge of the stresses at the surface and their depth distribution. An x-ray capability at Los Alamos is key to developing and maintaining industrial collaborations in strain effects. To achieve this goal, we implemented a residual strain measuring station on the rotating anode $x$-ray instrument at the Lujan Center. This capability has been used to investigate residual strains in heat treated automotive components, machining effects on titanium alloys, resistance welded steel joints, titanium matrix fiber reinforced composites, ceramic matrix composites, thin films, and ceramic coatings. The overall objective is to combine both $\mathrm{x}$-ray and neutron diffraction measurements with numerical models (e.g., finite element calculations).
\end{abstract}

\section{Background and Research Objectives}

The need to monitor and preserve the strength of materials during manufacture and service, coupled with component designs that utilize a greater percentage of the available strength, has been a strong driving force for nondestructive testing and numerical prediction of material properties. The measurement and prediction of residual stress is one aspect that has repeatedly proved important. Most failure mechanisms such as stress corrosion or fatigue cracking, as well as dimensional stability, are strongly affected by its presence. Residual stresses exist in the absence of external tractions and are categorized according to the length scales over which they act. Residual macrostresses are usually introduced by mechanical or thermal processes during manufacture and vary over distances measured in millimeters. Residual microstresses can result from interactions between phases, for instance in a composite, and vary over lengths determined by the microstructure (typically $1-100 \mu \mathrm{m}$ ).

*Principal Investigator, E-mail: joycer@lanl.gov 
In crystalline materials, diffraction is the measurement technique of choice. While no technique directly measures stress, diffraction is attractive because it records the lattice elastic strain directly instead of measuring a separate physical property that changes with stress. Furthermore, diffraction distinguishes between macro- and micro-stresses and indicates compositional and texture changes.

Residual strains exist throughout components and $\mathrm{x}$-rays or neutrons can probe different regions of the material. Whereas we have spent much effort pursuing the neutron option to measure internal strains, a complementary technique to study surface effects is of great value. Crack initiation frequently occurs at surfaces, due in part to surface flaws, but also due to residual stresses induced during manufacture, heat treatment, or machining. However, in fatigue crack initiation and stress corrosion cracking, microstresses, added to the macrostress, can cause large variation in the local stress intensity. X-rays are ideal for measuring surface stresses because of their shallow penetration. By having an on-site measuring capability at the Los Alamos Neutron Science Center (LANSCE) for both neutrons and $\mathrm{x}$-rays, we efficiently combine and compare the merits of the two approaches.

The development of a dedicated $\mathrm{x}$-ray capability at Los Alamos is not unique, but with the neutron diffraction opportunities and numerical expertise that already exist at Los Alamos, the combined capability provides a unique support suite for the emerging programs in material processing. Complementary $\mathrm{x}$-ray [1] and neutron diffraction measurements [2-6] offer full characterization of a specimen.

Our principal objective was to develop a strain measurement station on the rotating anode $\mathrm{x}$-ray machine at LANSCE. Many measurements require small spot sizes obtained by using a point source from the rotating anode with the associated intensity gain over a stationary machine of 1 to 2 orders of magnitude. By using different $\mathrm{x}$-ray energies, $\mathrm{Cr}$ $(5.4 \mathrm{keV}), \mathrm{Cu}(8 \mathrm{keV})$ and $\mathrm{Mo}(17.4 \mathrm{keV})$, some depth discrimination is possible. For mounting of large, weighty, and irregularly shaped engineering samples (compared to usual x-ray samples), a custom-designed goniometer was purchased. This goniometer, the only one of its kind to our knowledge currently available on the market, is constructed to accommodate specimens up to $50 \mathrm{~kg}$. A laser collimating device provides ease of alignment and ensuring safety, since sample alignment is accomplished without turning the $\mathrm{x}$-rays on. The system also consists of a position-sensitive detector and a system to rotate the monochromator so that the beam is in the horizontal plane. This capability is available to other researchers at Los Alamos and their collaborators.

Our second objective is to combine $\mathrm{x}$-ray and neutron scattering results to determine the range of applicability for specific problems. This is important since $\mathrm{x}$-rays are freely available but sometimes ambiguous, whereas access to neutrons is limited to a few sites but 
the results offer less ambiguity. Relatively few experiments $[7,8]$ have compared results of the two techniques. Finite-element modeling is used to correlate the bulk strains as measured by neutron diffraction with the surface strains measured by $x$-rays. The ultimate goal of using the combined approach of $\mathrm{x}$-rays and neutron measurements is that we can examine some of the fundamental aspects of strain development. This will lead to better predictions of bulk strains available from near surface measurements combined with finiteelement modeling. Examples are stresses in heat-treated automotive gears and anisotropy in matrix response of a metal-matrix composite observed during in-situ loading.

\section{Importance to Los Alamos's Science and Technology Base and National R\&D Needs}

In manufacturing, residual stress introduced during fabrication often resuits in the waste of time and resources due to distortion, cold cracking, and premature failure, necessitating the rejection or repair of components with obvious economic consequences. The importance of residual stress analysis is evident and is addressed in several Los Alamos initiatives concerning heat treatment, shot peening, and machining. The ability to make "in-house" $\mathrm{x}$-ray measurements in combination with the existing expertise of neutron diffraction strain measurement broadens Los Alamos's technology base for partnership with industry. Consolidation of this capability to the existing group makes efficient use of skill and personnel. By adding the $\mathrm{x}$-ray stress measuring capability to the neutron group, the validity of extrapolating $\mathrm{x}$-ray measurements to bulk properties can be checked as well as dual validation of modeling. This capability is used to support heat treatment distortion studies, science-based stockpile stewardship efforts, machining programs, and other LDRD projects.

This project enhances the Laboratory competency in nuclear and advanced materials. It addresses the field of prediction of materials lifetime through the development of improved finite-element codes and a better understanding of the results of diffraction measurements of residual strain. These areas are important for the development, processing, and use of advanced materials. In addition, this project is related to the Laboratory strategic plan implementation strategy to exploit increasing interest in problems related to residual strain in materials. 


\section{Scientific Approach and Accomplishments}

The measurement of residual stress by diffraction utilizes the spacing of the lattice planes as the gauge length of measuring strain. A change in stress results in a modification of the interplanar spacings which, with a monochromatic $x$-ray beam, alters the angular position of the diffraction peaks. The variation of the interatomic spacing as a function of the angle $y$ between the surface normal and the direction of the strain being measured can be determined. In general the principal stress directions are assumed to lie in the surface and the normal stress is taken to be zero. Three principal methods exist: the $\sin ^{2} y$ method and the one- and two-tilt methods. In the $\sin ^{2} y$ method, the most commonly used, the lattice spacing is determined by measurements at various $y$ angles to the particular hkl plane of interest. For classical $\mathrm{x}$-ray stress analysis, these data are linear and the surface component of the stress can be determined from fitting the data (see Figure 1). Nonlinear relationships of the data arise from steep stress gradients that change in less than the penetration depth of the x-rays, from texture, and from large shear components in the sample. Complementary measurements at a neutron source do not require assumptions about the normal stress and thus are less vulnerable to causes of nonlinearity noted above. At spallation neutron sources, pulses of neutrons are used. The wavelength of a detected neutron is determined from its time of flight between its creation by the spallation process and its arrival at the detector. Thus the specimen is scanned in wavelength, and after many pulses a spectrum containing all the lattice spacings is collected. The strain is determined from the shift in time-of-flight of the diffraction peak.

\section{Residual Stress \& Microstructure Characterization Using X-rays \&} Neutrons. [9-12]. Surface strain measurements of round robin samples, gear-like blanks (called pucks), associated with the Heat Treatment Distortion Project (HTDP) have been made at the Manuel Lujan, Jr. Scattering Center (MLNSC) and at other facilities of the participating laboratories. The goals achieved were demonstration of $\mathrm{x}$-ray residual-stress depth-profiling measurement and comparison of the accuracy of $x$-ray and neutron residualstress profiling methods. This was an ambitious goal since the problem involved steep stress gradients, partial immersion of a neutron sampling volume, and microstructural variations. This study was the first known comparison of results through a carburized layer obtained by neutron strain mapping with those from $\mathrm{x}$-ray diffraction depth profiling using the electropolish removal method.

Measurements were on 5120 steel heat-treated pucks (Figure 2a), similar material to that of the gears to be studied, so that demonstrated capabilities and knowledge of accuracy can guide selection of the most appropriate residual stress methods for use in providing 
essential stress data of known accuracy for comparison with constitutive model results. The objective of these measurements was to explore the viability of using neutron diffraction to profile a macrostress distribution nondestructively through a carburized layer. The potential advantages of using neutrons, rather than $x$-rays, arise from the avoidance of layer removal and the associated implicit corrections. Additionally there is the potential to reach regions not accessible to $\mathrm{x}$-rays without sectioning. The results, presented in Figure $2 \mathrm{~b}$, suggest that neutron measurements can qualitatively describe the macrostress field, however there are differences in detail with the complementary $\mathrm{X}$-ray profile.

Although the peak stresses are comparable, there are discrepancies in the depth of the maximum stress and in the behavior less than $1 \mathrm{~mm}$ from the surface (Fig. 2b). The peak stress measured by $\mathrm{x}$-rays occurs approximately $0.4 \mathrm{~mm}$ below the surface (there are many measurements, not reported here, that support this assertion). Conversely, the neutron compressive maximum is closer to $0.15 \mathrm{~mm}$ below the surface. Ignoring the possibility of differences between the two specimens (it would have been preferable to do both measurements on the same puck), the most likely explanation is a positional error in the neutron results compounded by the center-of-gravity approximation used to locate the near surface measurements. Precise location of the neutron sampling volume to an accuracy of $0.1 \mathrm{~mm}$ is difficult near the surface. The other significant discrepancy arises below $1 \mathrm{~mm}$ where the $\mathrm{x}$-ray measurements fail to show the balancing tensile stress that must, from equilibrium considerations, be present. This is the region where the neutron measurements should excel by virtue of their deep penetration and the more moderate stress gradient. Indeed, the neutron results do indicate a small tensile stress extending into the interior of the puck. The probable explanation is that by $1 \mathrm{~mm}$, the $\mathrm{x}$-ray measurements are vulnerable to compounded errors and to the validity of the layer removal correction. Comparison of neutron and $\mathrm{x}$-ray results showed that the maximum stresses were within $20 \%$ of one another, but there were differences in the location and in the profile deeper than $1 \mathrm{~mm}$ from the surface.

The x-ray and neutron results are compared with the predictions based on the codes used in the HTDP. The compliance method for measuring residual stress variation with depth is also shown. Briefly, in a compliance method a slot is incrementally introduced into a part containing residual stress, causing local relaxation. The resulting surface strains are measured at each increment of slot depth and used to solve for the residual stresses originally existing in the part. It is a more mechanistically derived method and less sensitive to microstructural effects. Even though the $\mathrm{x}$-ray and neutron results where obtained from a puck, and the results obtained from crack compliance and the predictions 
are for a true gear blank, measurements made on a true gear blanks using $\mathrm{x}$-rays showed similar profiles between the two geometries.

In comparing the results obtained from diffraction techniques and crack compliance, it is clear that the crack compliance technique shows a smooth variation in the stress profile. This suggests that the macrostress profile is essentially unaffected by the microstructural variations within the case, and the peak maximum and the cross-over from compression to tension agree reasonably well with the predictions. However, meaningful stress values using the crack compliance can only be obtained after about 100 microns depth below the surface. To obtain a more accurate stress determination using the diffraction methods, the following limitations must be overcome: the presence of retained austenite in the case, contributing to the microstress, has to be taken into consideration; the unstressed lattice spacing $d_{0}$ has to be corrected for changes in chemical composition in the case; the assumption of plane stress through the case (neutron data) may be an over-simplification and not justified; and layer removal corrections ( $\mathrm{x}$-ray data) are for a complete removal of a layer in a semi-infinite plate, whereas in practice material was removed in a localized region using a circular geometry.

Complementary depth profiles of residual stress and microstructure were also recorded and analyzed through a carburized layer using $x$-ray diffraction techniques and the Rietveld method [13]. One issue of paramount importance to the accurate prediction of distortion is the carbon profile. This is usually measured independently using burn-up or microprobe methods or by inference from hardness measurements, but the lattice parameters of both austenite and martensite provide an independent source for the carbon profiles $[14,15]$. By combining Rietveld refinements of $x$-ray diffraction patterns and stress measurements using conventional $x$-ray techniques, through the carburized case, microstructural effects on the lattice distortion due to strain can be separated. In addition, this also provides an independent mechanism for determining carbon content, of extreme usefulness for providing validation support to numerical modeling (Fig. 3).

The carbon profiles predicted by Rietveld analysis correlate with the extent of decarburization measured using burn-out/combustion techniques. This is also supported by the hardness measurements where the drop in the hardness value can be attributed to a decarburized region. The numerical simulations are compared with experimental results for carbon content. The carbon content below 350 microns shows an excellent agreement between the experimental measurements and finite-element model predictions, but closer to the surface the agreement is qualitative between the experimental measurements but clearly in disagreement with the finite-element model predictions. Metallographic examinations clearly indicated the effects of decarburization and presence of both austenite and martensite 
in the case region. Further investigations into the modeling capability to address the possible ways to account for decarburizing are ongoing.

Studies of Oxide Scale Stresses in Polycrystalline Copper CuO/Cu${ }_{2} \mathrm{Or}$ $[16,17]$. Researchers have been interested in understanding the origin and nature of residual stresses in oxide scales developing on metal/alloy surfaces [18-21]. This in turn could lead to better understanding of protection of metals from oxidation and corrosion. Oxidation of copper leads to the formation of $\mathrm{CuO}$ and $\mathrm{Cu}_{2} \mathrm{O}$, the amounts of which depend on the temperature of oxidation. Residual stresses in oxide scales develop due to both volume change between the metal and the oxide (Pilling-Bedworth-Ratio, PBR) and the coefficient of thermal expansion mismatch between the oxide and the base metal. In this study $x$-ray diffraction was used to determine the oxidation stresses at room temperature in annealed and electropolished samples of polycrystalline $\mathrm{Cu}$ coupons of different thickness $(0.75,1.25$, and $2.25 \mathrm{~mm})$ oxidized for 15 and 30 minutes at temperatures of $700^{\circ}, 800^{\circ}$, and $900^{\circ} \mathrm{C}$. Residual stresses determined in the $\mathrm{Cu}_{2} \mathrm{O}$ phase are presented in Figures $4 \mathrm{a}$ and $4 \mathrm{~b}$. In this system, the average stresses on the free surface of the oxide were compressive and independent of orientation in the plane of the surface. The average stress through the thickness normal to the oxide layer was found to be tensile. Since both the metal substrate and the oxide scales were made of randomly oriented polycrystals, the residual oxide scale stresses were generally found to be independent of surface orientation. These trends are consistent with observations in other metal-oxide systems, e.g. Ni-NiO $[21,22]$. The considerably lower value of the coefficient of thermal expansion for the oxide scale as compared to the substrate and a PBR of 1.64 for the $\mathrm{CuO} / \mathrm{Cu}_{2} \mathrm{O}$ system are the chief contributors to these residual stresses.

The oxide scale stresses in $\mathrm{Cu}_{2} \mathrm{O}$ exhibit interesting trends with respect to temperature and time of oxidation and metal substrate thickness. These results are examined in the context that oxidation of copper leads to the formation of varying contents of $\mathrm{CuO}$ and $\mathrm{Cu}_{2} \mathrm{O}$. In general, at any oxidation temperature, increasing the metal substrate thickness resulted in substantial increase in stress values, while increasing the oxidation time affected the stress values marginally. Also, increasing the oxidation temperature substantially reduced the stress values. Due to the preliminary nature of the present work the development of a complete phenomenological model for explaining all the observations is not possible. However, some of the observations may be explained. For example, the increase in the oxide scale stress due to increasing metal substrate thickness can be explained from a simple balance of force analysis. As long as the oxide mechanical integrity and adhesion to the substrate is preserved, this results in increased stress values. To attain a full understanding of the problem, both micromechanical analyses and additional 
measurements in $\mathrm{CuO}$ need to be done. Further phase and microstructural analyses are needed to understand the marginal effect of time and the substantial effect of higher temperature on the oxide scale stresses. This in turn would help in the understanding of residual stresses in ceramic coatings.

The Influence of Thermal-Mechanical Processing on Residual Stresses in Titanium Matrix Composites (SCS-6(SiC)/Ti-6Al-2V-4Sn-2Mn) [23,24]. Most titanium alloys, in their unreinforced form, show fatigue sensitivity to cyclic stress. Consequently, in a composite, it is likely that the presence of residual stress will impact the fatigue performance by modifying the effective mean stress in the matrix [25]. In practice residual stresses will vary with geometry and processing parameters. Accordingly it may be necessary to monitor residual stresses in titanium matrix composites (TMC) for assurance of adequate remaining fatigue life. By understanding the evolution of residual stresses during thermomechanical processing it may be possible to introduce controlled processing for improved fatigue performance $[26,27]$.

In this study the effects of three distinct thermomechanical processes on the residual stress state in a unidirectionally reinforced SCS-6/Ti-6-2-4-2 [0] $]_{6}$ were predicted using a - finite-element model. The processes were : 1) cooling under longitudinal tension, 2) cooling under transverse compression, and 3) hydrostatic pressurization at room temperature. Residual stresses were determined using $\mathrm{x}$-ray and neutron diffraction to validate the predictions. $X$-rays have routinely been used to monitor residual stresses in TMCs after fabrication or during the course of fatigue testing (thermal, thermomechanical, isothermal and mechanical) since there is a substantial matrix layer above the fibers $[7,8]$. In some instances the surface values are unrepresentative of the interior [8]. In contrast to the $\mathrm{x}$-ray measurements, neutrons, because of their deep penetration, provide mean phase strain information, as distinct from surface information. Neutrons also characterize the reinforcement as well as the matrix. This provides an independent check of stress balance in the fiber direction and means of verification of the strain measurements. Taken together, the approach of using both $\mathrm{x}$-ray and neutrons provides surface and bulk stress values, respectively, so that a comparison for monitoring changes in stresses due to processing is provided.

During the course of measurements using neutrons, a very interesting observation on the strain distribution around the fiber and in the plane of the composite was found. The variation of strain around the fiber remained fairly constant supporting the assumption of transverse isotropy used in the finite-element models. The variation of strain in the plane of the composite fit to the following equation $\left\langle e_{\mathrm{a}}\right\rangle_{\mathrm{i}, \mathrm{m}}=\left\langle\mathrm{e}_{11}\right\rangle_{\mathrm{f}, \mathrm{m}} \cos ^{2} \mathrm{a}+\left\langle\mathrm{e}_{22}\right\rangle_{\mathrm{f}, \mathrm{m}} \sin ^{2} \mathrm{a}$, where $\mathrm{f}$ and $\mathrm{m}$ are fiber and matrix respectively. Even though the physical basis of this equation is 
poorly understood, it is consistent with a plane stress state condition on a surface if the $\mathrm{x}$ ray measurement directions are the principal stress directions. In comparing the experimental results with the finite-element model predictions, qualitative agreement with both $\mathrm{x}$-ray and neutron measurements was achieved, but there was magnitude disparity. Even though it was found that the maximum residual stress changes are not substantial relative to the as-fabricated state, their effects on the fatigue life cycle may be significant [27]. Ultimately the value of these processes will be determined from improvements, or lack thereof, in fatigue lifetimes. Some measured fatigue data are compared with stress values in Figure 5. Fatigue lifetimes are plotted against the measured or predicted stresses. The trend of improved lifetime for reduced residual stress can be seen for the matrix stresses showing that the matrix mean stress has a similar influence on the performance of the composite as in unreinforced titanium alloys.

\section{$X$-ray Measurements of ResidualStresses Around the Weld of a}

Stainless SteelJoint.. Approximately $20 \mathrm{x}$-ray stress measurements were performed on the surface of a stainless steel $(21 \mathrm{Cr}-6 \mathrm{Ni}-9 \mathrm{Mn})$ specimen containing a resistance forge weld (Fig. 6). The $\mathrm{x}$-ray penetration depth is only a few $\mu \mathrm{m}$ and thus $\mathrm{x}$-rays and neutrons are complementary techniques looking at the surface and interior respectively. The stress values recorded were within $50 \%$ of those predicted using a numerical code at Los Alamos. However, significant circumferential variations in the stress profile were recorded around the part. Since the numerical code was axisymmetric, it did not take these variations into account, and the experimental measurements suggest that a three-dimensional calculation may be needed. More importantly, it suggests that the current fabrication procedure does not result in a uniform weld and that the weld forms irregularly around the base or edge of the part.

\section{Publications}

1. Partha Rangaswamy, Mark A. M. Bourke, Ning Shi, Bruce Dennison, Joyce A. Roberts, "The contribution of matrix alloy to the residual stresses of three classes of Titanium Matrix Composites", to be published in Met. Trans. - 1997.

2. Prime, M. B., and P. Rangaswamy, "Measuring Residual Stress Using the Compliance Method: Theory and an Application," Society of Engineering Science 33rd Annual Technical Meeting, Book of Abstracts, October 20-23, 1996, Tempe, AZ, pg. JG4.

3. P. Rangaswamy, Mark A. M. Bourke \& Joyce A. Roberts "Neutron Residual Strain Measurements in a highly textured Ti-6242/SiC Metal Matrix Composite," To be published in Scripta Metallurgica - 1996. 
4. P. K. Wright, P. Rangaswamy \& Mark A. M. Bourke, "Effect of Residual Stress on Fatigue of a Titanium Matrix Composite," accepted for publishing in Composites Part B Engineering Journal, published by Elsevier Science, London, 1996.

5. C. Anderson, P. Goldman, P. Rangaswamy, T. Lowe, et al., "Development of a Carburizing and Quenching Simulation Tool: Numerical Simulation of Rings and Gears", ASM Heat Treating Society - Second International Conference on Quenching and Control of Distortion, Detroit, Michigan, October 1996.

6. P. Rangaswamy, M. A. M. Bourke, P. K. Wright, E. Kartzmark, J. Roberts \& N. Jayaraman, "Influence of residual stresses on the Thermo-mechanical processing of SCS-6/Ti-6-2-4-2 Titanium Metal Matrix Composites," accepted for publication in Material Science \& Engineering (1996).

7. M. A. M. Bourke, P. Rangaswamy, T. M. Holden, R. Leachman, "Complementary neutron and $\mathrm{x}$-ray measurements in an attempt to obtain a strain profile through a carburized layer", accepted for publication in Material Science \& Engineering (1996).

8. P. Rangaswamy, M. A. M. Bourke, A. C. Lawson, J. O'Rourke, and J. A. Goldstone, Residual stress and microstructural characterization using Rietveld refinement of a carburized layer in a 5120 steel, Accepted for publication in Vol. 39, Advances in X-ray Analysis (1995).

9. N. Jayaraman, P. Rangaswamy, Oxide Scale Stresses in Polycrystalline $\mathrm{Cu} / \mathrm{Cu}_{2} \mathrm{O}$ System, Accepted for publication in Vol. 39, Advances in X-ray Analysis (1995).

\section{References}

1. I. C. Noyan and J. B. Cohen, Residual Stress: Measurement by Diffraction and Interpretation. (Springer-Verlag, New York, New York,) 1987.

2. M. A. M. Bourke, J. A. Goldstone, M. G. Stout, A. C. Lawson, and J. E. Allison, "Strain Measurement in Individual Phases of an Al/TiC Composite during Mechanical Loading," in Residual Stresses in Composites: Measurement, Modeling, and ThermoMechanical Modeling (ed. E. V. Barrera and I. Dutta, The Minerals, Metals, and Minerals Society (TMS), Proceedings 122nd TMS Annual Meeting) Denver CO, Feb. 21-25, 1993.

3. Steve Spooner, S. A. David, J. H. Root, T. M. Holden, M. A. M. Bourke, and Joyce Goldstone, "Residual Stress and Strain Measurements in an Austenitic Steel Plate Containing a Multipass Weld", in Proceedings, Third International Conference on Trends in Welding Research, American Society of Metals, publisher, Metals Park, OH 1993.

4. G. L. Povirk, M. G. Stout, M. Bourke, J. A. Goldstone, A. C. Lawson, M. Lovato, S. R. MacEwen, S. R. Nutt, and A. Needleman, "Thermally and Mechanically Induced Residual Stresses in Al-SiC Composites" Acta Met. Mater. 40 (1992) pp. 2391-2412.

5. T. M .Holden, R. R. Hobsons, S. R. MacEwen, E. C. Flower, M. A. M. Bourke, and J. A. Goldstone, "Comparison between Finite Element Calculations in Complex Parts 
and Neutron Diffraction", Measurement of Residual and Applied Stress using Neutron Diffraction, (edited by M. T. Hutching and A. D. Krawitz, Kluwer Acad. Pub., Netherlands, 1992), pp. 93-112.

6. M. A. M. Bourke, J. A. Goldstone, and T. M. Holden, "Residual Stress Measurement using the Pulsed Neutron Source at LANSCE", Measurement of Residual and Applied Stress using Neutron Diffraction, (edited by M. T. Hutching and A. D. Krawitz, Kluwer Acad. Pub., Netherlands, 1992), pp. 369-382.

7. M. R. James, M. A. Bourke, J. A. Goldstone and A. C. Lawson: "Residual Stress Measurements in Continuous Fiber Titanium Matrix Composites", Advances in X-ray Analysis, Vol. 36 (1993).

8. M. R. James, M. A. M. Bourke, J. A. Goldstone, and A. C. Lawson, "Diffraction Measurements of Residual Stress in Titanium Matrix Composites, in "Residual Stresses in Composites: Measurement, Modeling, and ThermoMechanical Modeling (edited by E. V. Barrera and I. Dutta, TMS , Proceedings 122nd The Minerals, Metals, and Minerals Society (TMS) Annual Meeting) Denver CO, Feb. 21-25, 1993.

9. M. A. M. Bourke, P. Rangaswamy, T. M. Holden, R. Leachman, "Complementary neutron and $\mathrm{X}$-ray measurements in an attempt to obtain a strain profile through a carburized layer", accepted for publication in Material Science \& Engineering (1996).

10. P. Rangaswamy, M. A. M. Bourke, A. C. Lawson, J. O'Rourke, and J. A. Goldstone "Residual stress and microstructural characterization using Rietveld refinement of a carburized layer in a 5120 steel," Accepted for publication in Vol. 39, Advances in Xray Analysis (1995).

11. C. Anderson, P. Goldman, P. Rangaswamy, T. Lowe, et al., "Development of a Carburizing and Quenching Simulation Tool: Numerical Simulation of Rings and Gears", ASM Heat Treating Society - Second International Conference on Quenching and Control of Distortion, Detroit, Michigan, October 1996.

12. Prime, M. B., and P. Rangaswamy, "Measuring Residual Stress Using the Compliance Method: Theory and an Application," Society of Engineering Science 33rd Annual Technical Meeting, Book of Abstracts, October 20-23, 1996, Tempe, AZ, pg. JG4.

13. R. B. Von Dreele, J. D. Jorgensen \& C. G. Windsor, Journal of Applied Crystallography, 15, 581-589, 1982.

14. C. S. Robert, "Effect of Carbon on the Volume Fractions and Lattice parameters of Retained Austenite and Martensite", Trans. AIME, Journal of Metals, Feb., 1953, pp. 203-204.

15. Zenji Nishiyama, Martensitic Transformation,, M. E. Fine, M. Meshii, and C.M. Wayman, Eds., Academic Press, NY (1978), pp. 14 - 20.

16. N. Jayaraman, $P$. Rangaswamy, Oxide Scale Stresses in Polycrystalline $\mathrm{Cu} / \mathrm{Cu}_{2} \mathrm{O}$ System, Accepted for publication in Vol. 39, Advances in X-ray Analysis (1995).

17. N. Jayaraman and M. J. Verrilli, Journal of Materials Science, 24 (1989) 1327-1331. 
18. N.B. Pilling and R. E. Bedworth, Journal of Institute of Metals, Vol. 29, (1923), p.259.

19. Conference on "Mechanical properties and adherence of scale layers and their influence on the oxidation of metals", Werkstoffe und Korrosion, Vol. 23, (1972).

20. "Stress effects and the oxidation of metals", edited by J. V. Cathcart, TMS-AIME, New York, (1975).

21. D. L. Douglass, “Oxidation of Metals”, Vol. 1, (1969), p 127.

22. N. Jayaraman and M. J. Verrilli, Journal of Materials Science, 24 (1989) 1327-1331.

23. P. Rangaswamy, M. A. M. Bourke, P. K. Wright, E. Kartzmark, J. Roberts and N. Jayaraman, "Influence of residual stresses on the Thermo-mechanical processing of SCS-6/Ti-6-2-4-2 Titanium Metal Matrix Composites," accepted for publication in Material Science \& Engineering (1996).

24. P. K. Wright, P. Rangaswamy and Mark A. M. Bourke, "Effect of Residual Stress on Fatigue of a Titanium Matrix Composite," accepted for publishing in Composites Part B Engineering Journal, published by Elsevier Science, London 1996.

25. M. Doner, K. R. Bain and J. H. Adams " Evaluation of Methods for the Treatment of Mean Stress Effects on Low-Cycle Fatigue", ASME Paper 81-GT-122.

26. W. S. Johnson, S. J. Lubowinski, and A. L. Highsmith: Thermal and Mechanical Behavior of Ceramic and Metal Matrix Composites, ASTM STP 1080, J. M. Kennedy, H. H. Moeller, and W. S. Johnson, Eds. Philadelphia, 1990, pp. 193-218.

27. H. Gigernzer, and P. K. Wright: “ Plasma Sprayed SCS-6/Titanium Aluminide Composite Test Panels", Titanium Aluminide Composites, P. R. Smith, S. J. Balsone, and T. Nicolas, Eds., WL-TR-91-4020, pp. 251-264. 


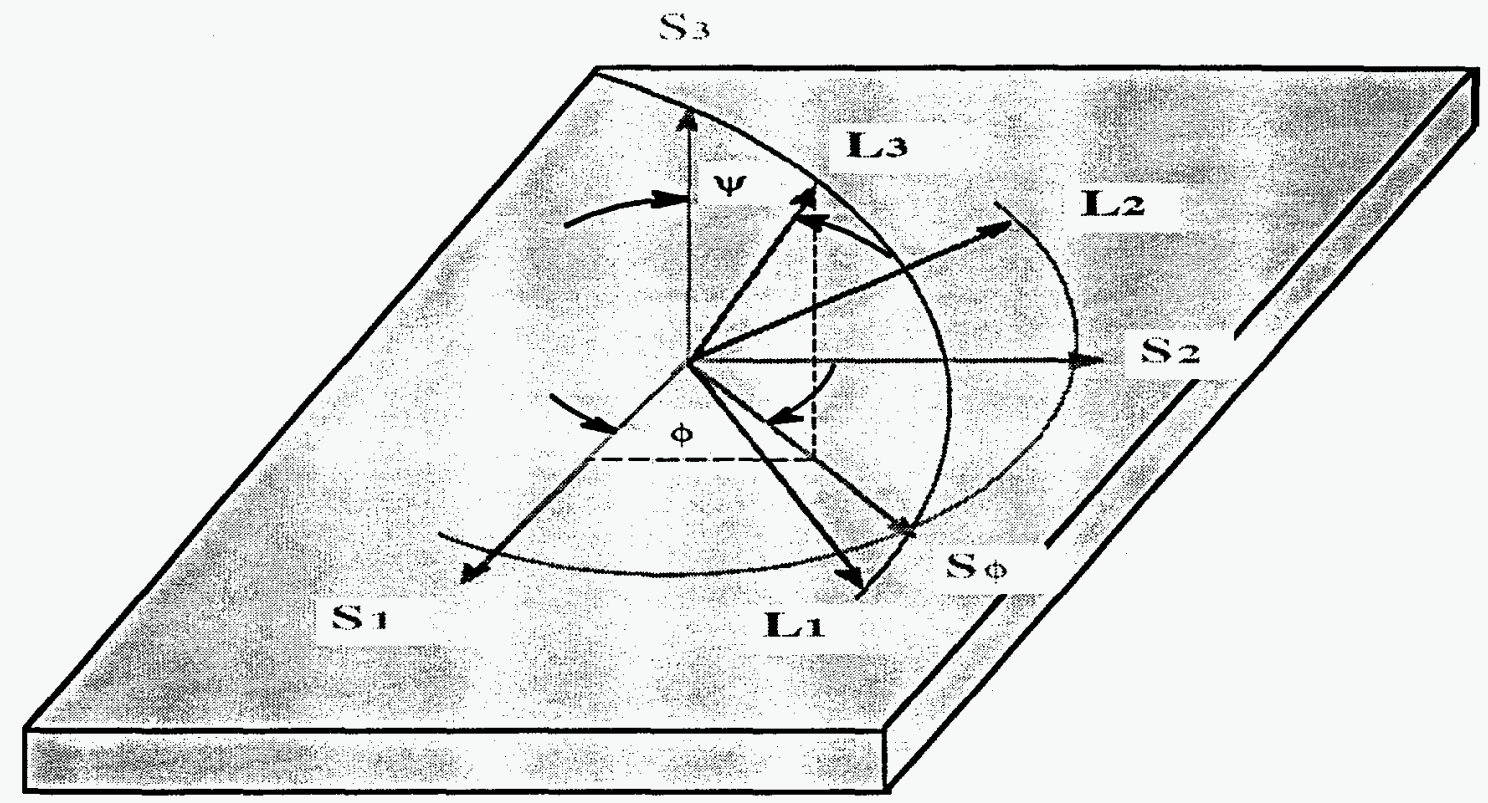

Figure 1a. Geometry of sample and diffraction. The axes labeled $S_{i}$ are the specimen axes and $L_{i}$ are the laboratory axes. $L_{3}$ is the diffracting plane normal. For a given specimen interplanar spacings were measured for angles $\mathrm{y}=0,15,30,45$ and $60^{\circ}$ and angles $\mathrm{f}=0$ and $90^{\circ}$. 


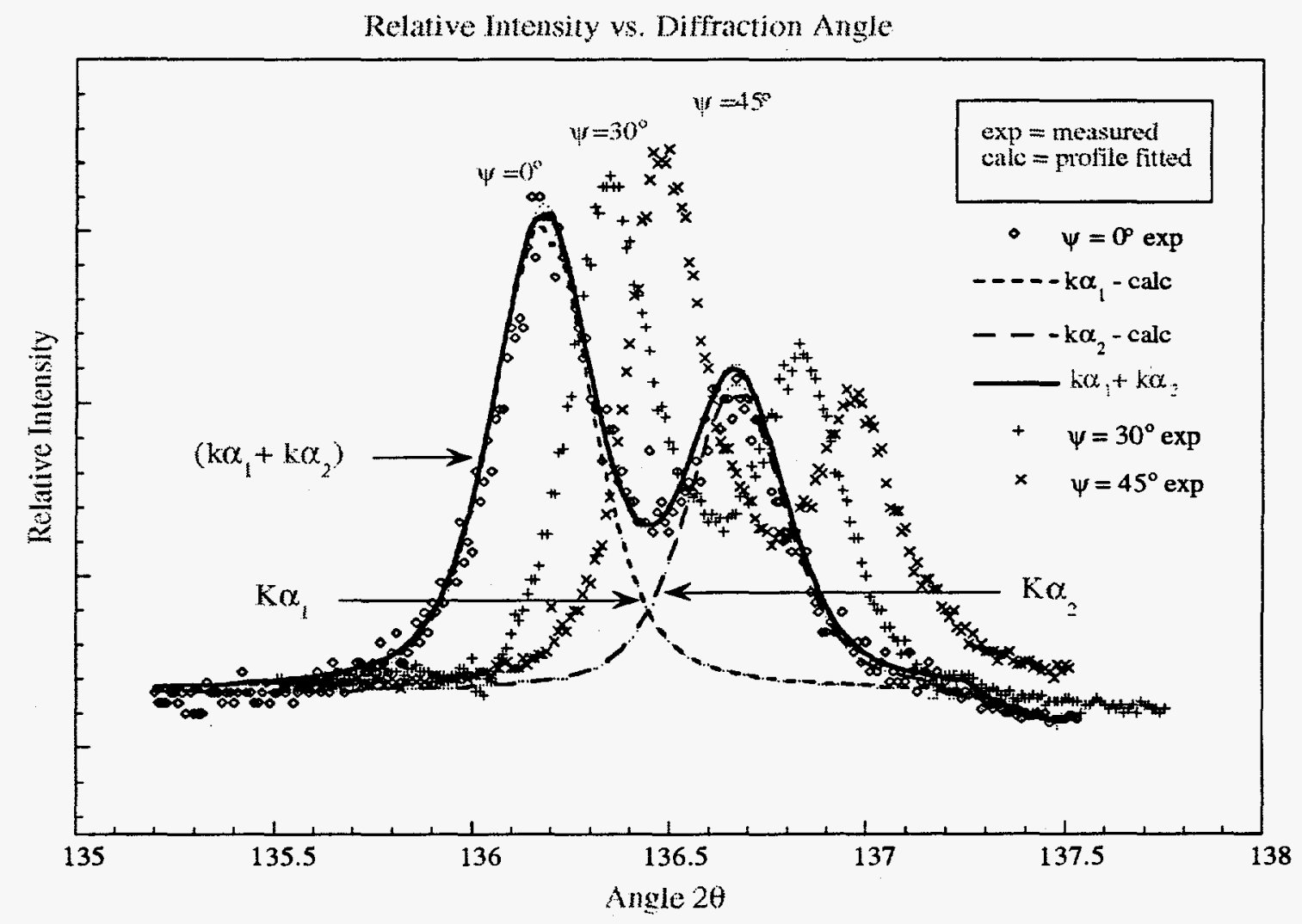

Figure 1b. A typical set of scans indicating the effect of stresses on the relative position of the hkl $\{222\}$ peak for various y-angles $\left(\mathrm{Cu}_{2} \mathrm{O}\right.$ phase). 


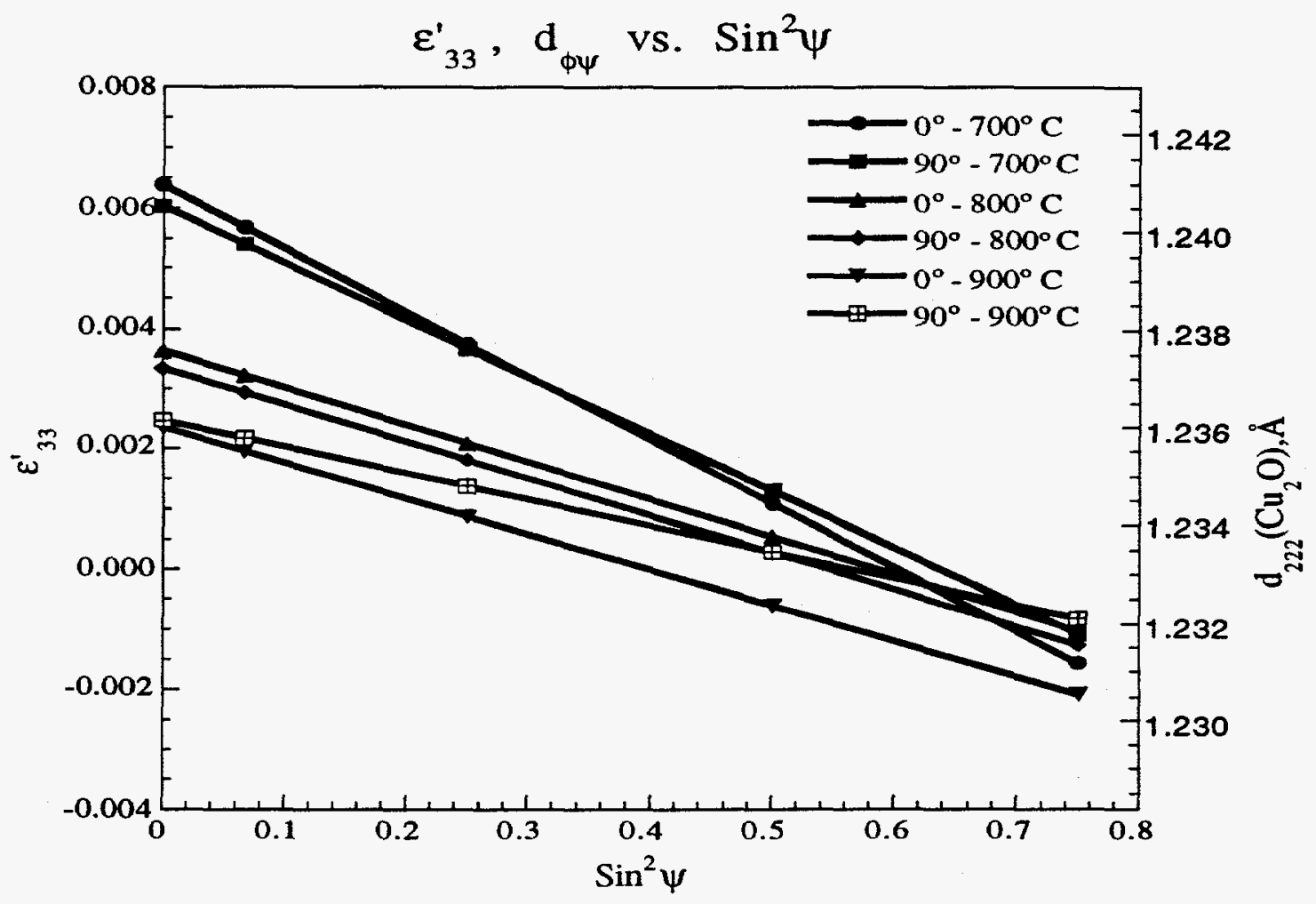

Figure 1c. Typical d vs. $\operatorname{Sin}^{2} y$ plots used for obtaining stress in any direction (f) on the sample surface. 


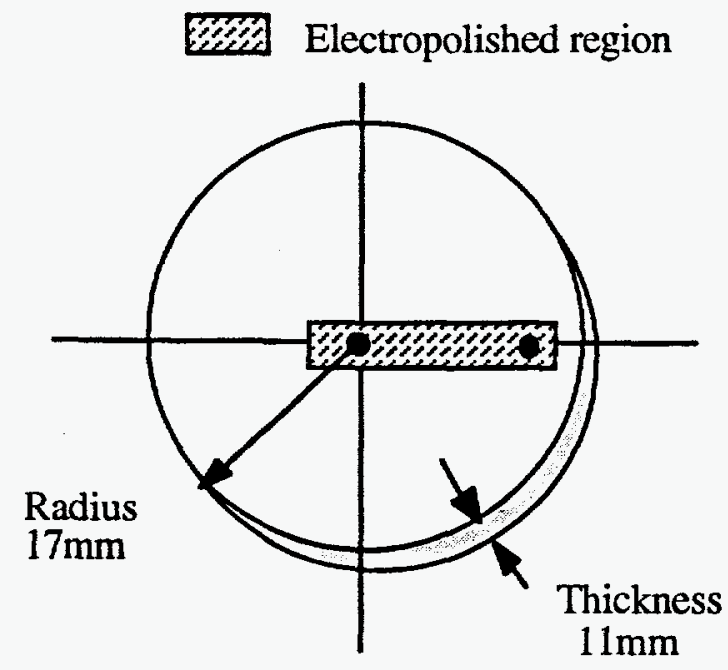

(a)

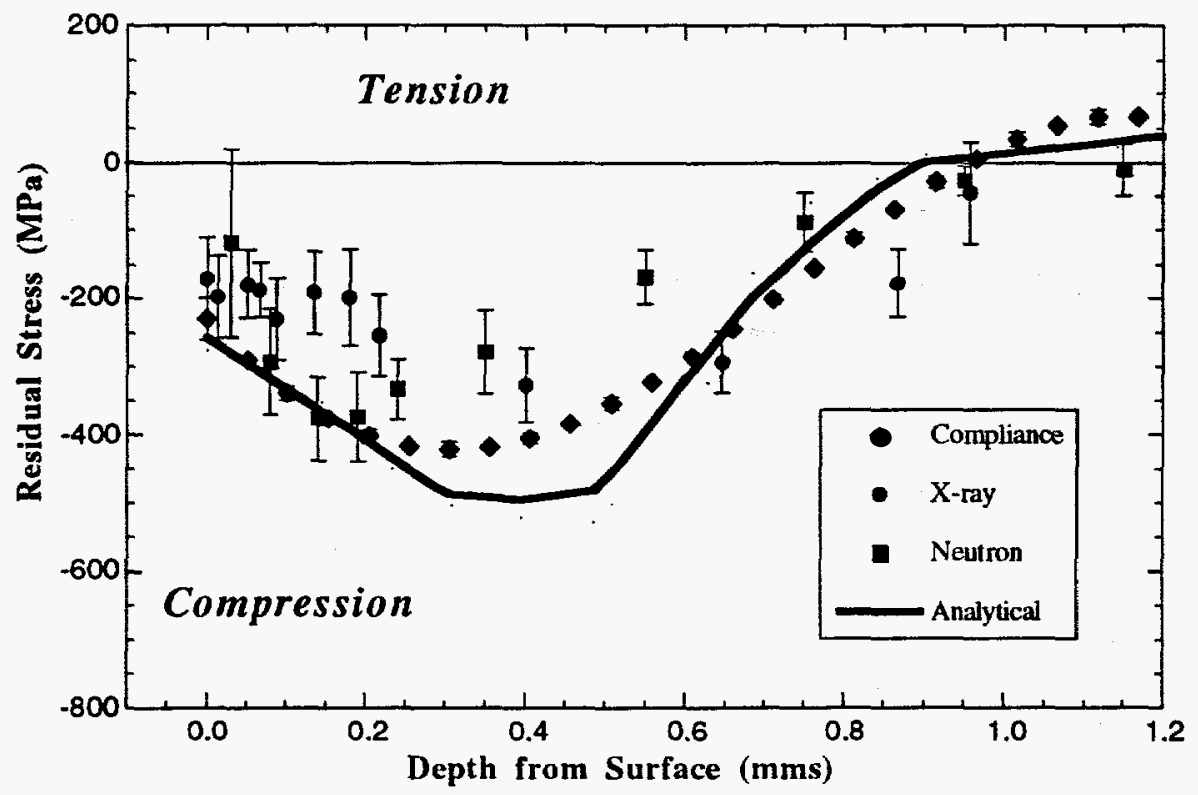

(b)

Figure 2. (a)Schematic of the gear blank. Shaded area shows the region electropolished for $\mathrm{x}$-ray measurements. The measurement locations are indicated by the solid circles $(\bullet)$. (b) Results from tests on a case hardened steel ring. 


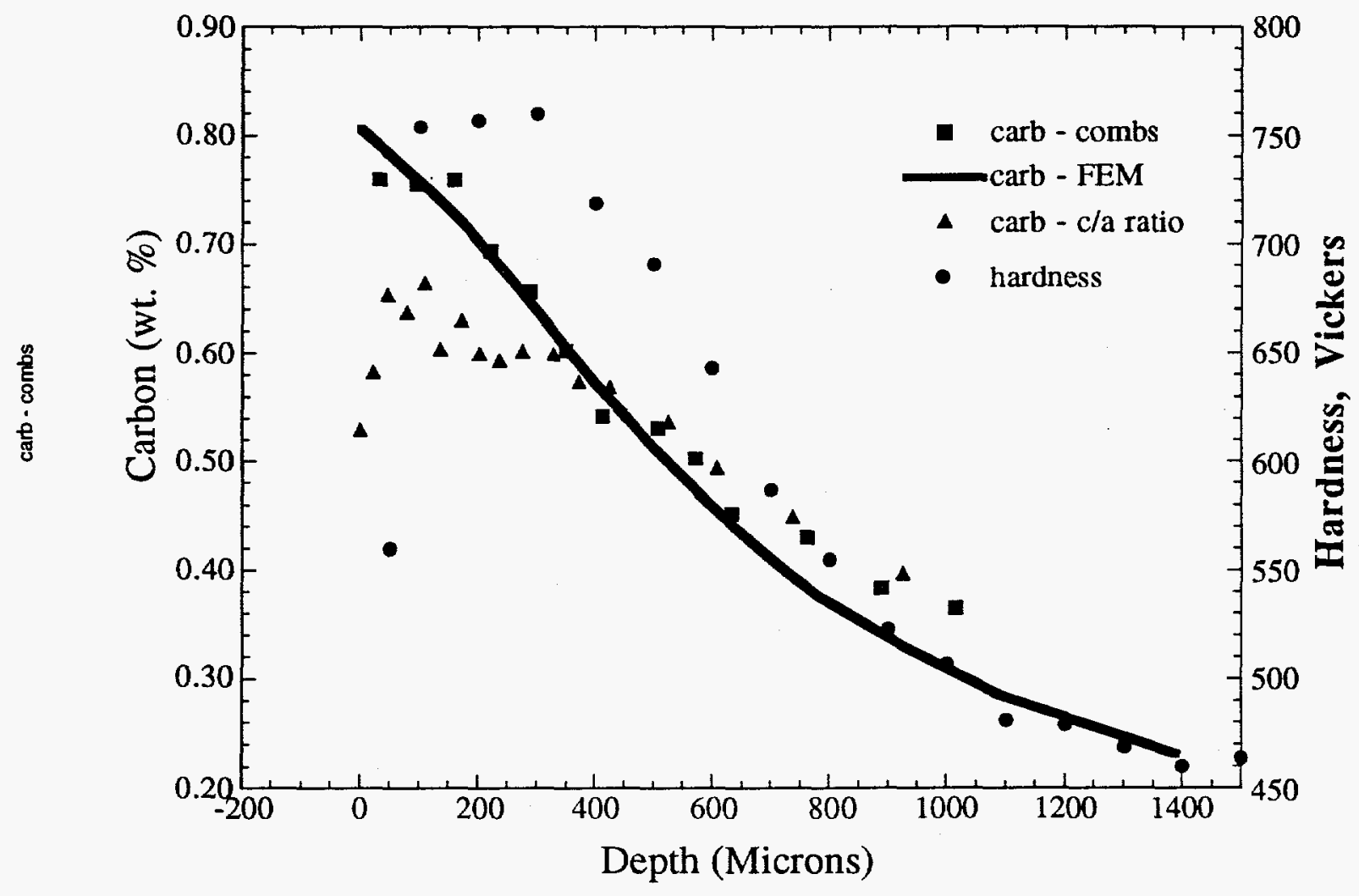

Figure 3. Comparison of carbon profiles between prediction from ABAQUS, calculations of lattice parameters and experimental measurements using combustion (burn-up) technique. Hardness measurements are also shown which support qualitatively the carbon profiles obtained through measurement techniques. 


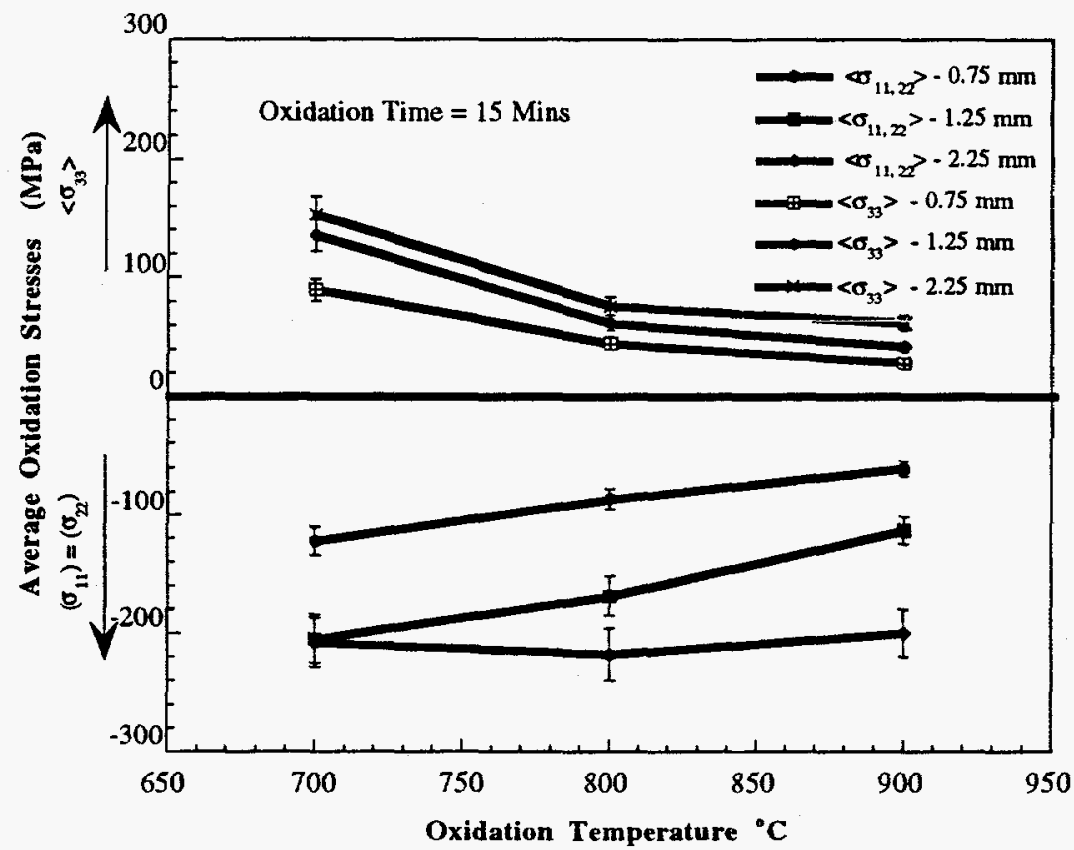

(a)

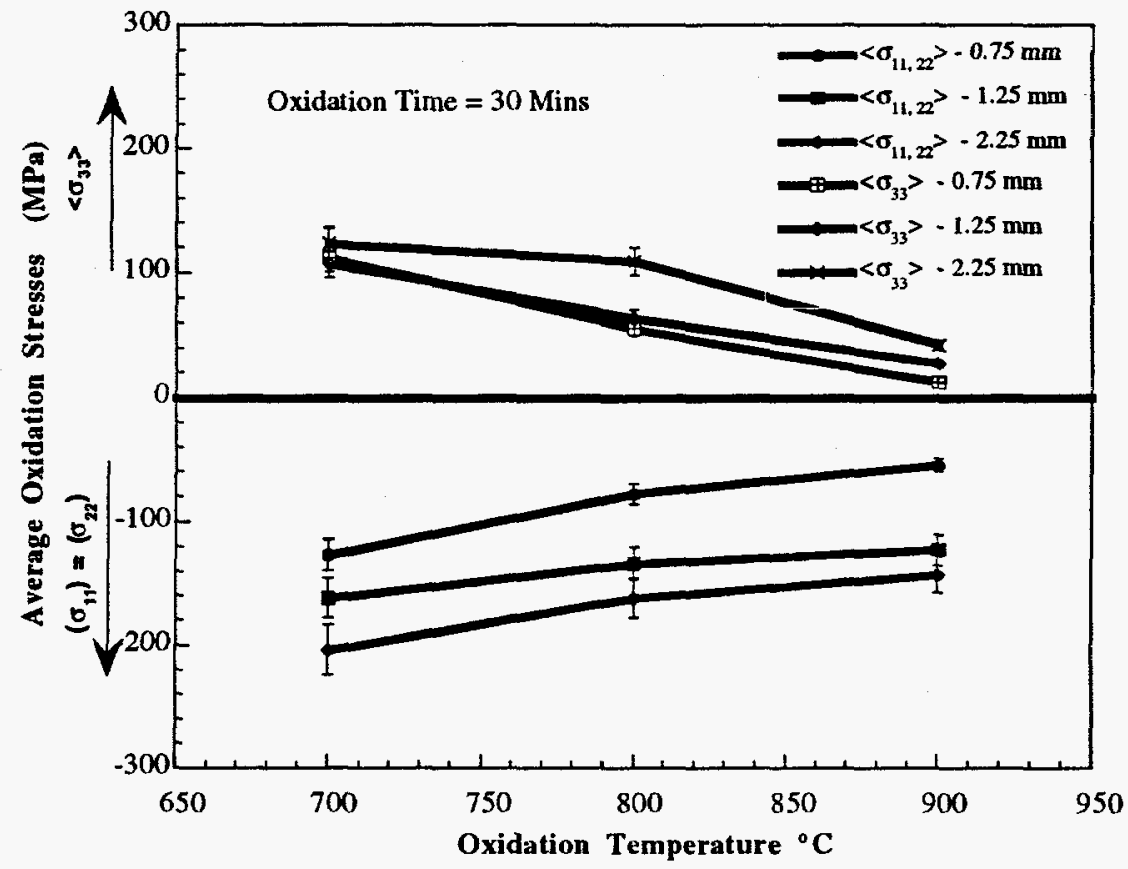

(b)

Figure 4. Plots of in-plane and average normal stresses against oxidation temperature and sample thicknesses for an oxidation time of (a) 15 mins and (b) 30 mins respectively. 


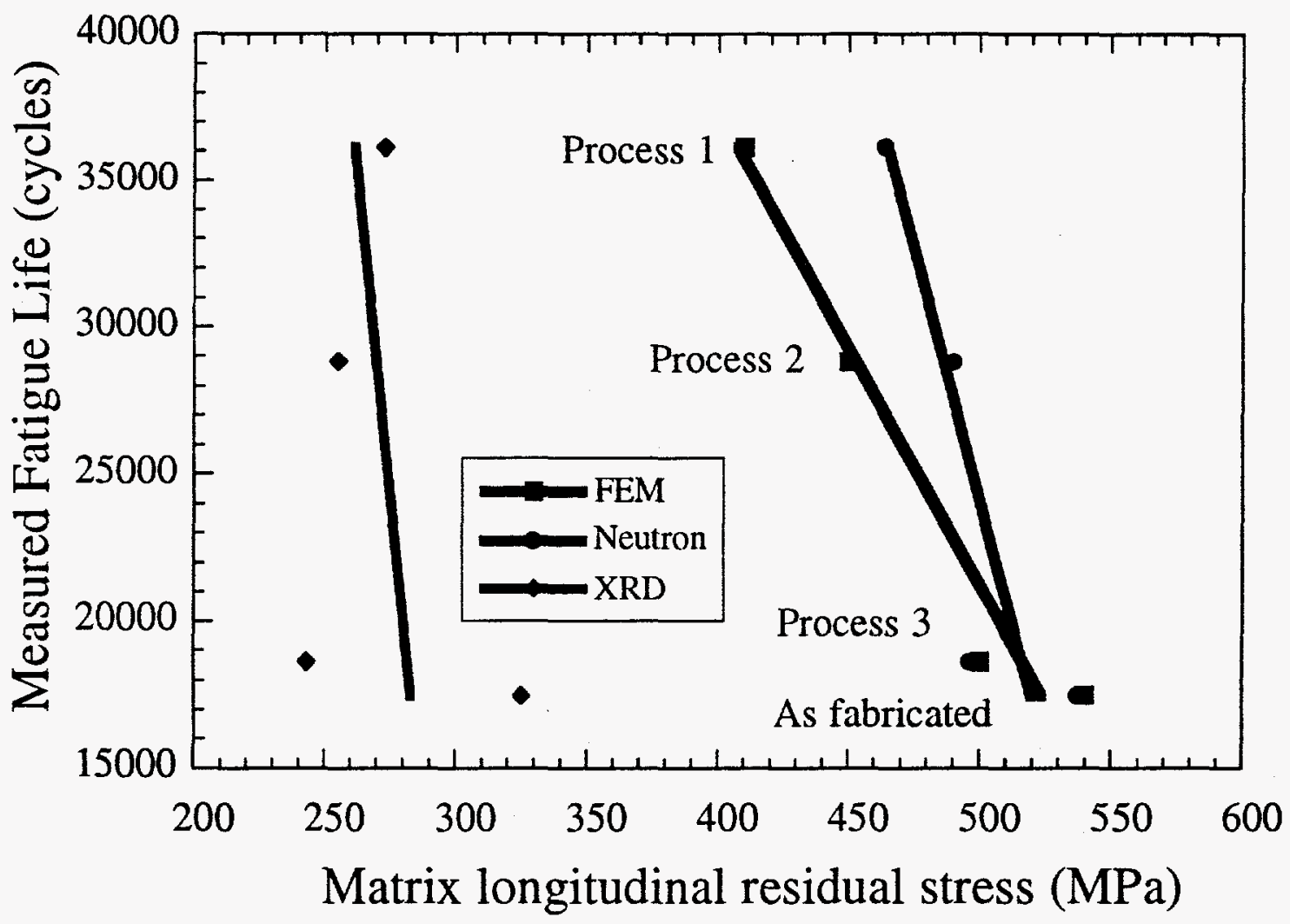

Figure 5. Experimentally measured longitudinal fatigue lifetimes plotted against finite element and experimentally determined longitudinal stresses. (Room temperature fatigue @ $960 \mathrm{MPa}$ with $\mathrm{R}=0.025$ ). 


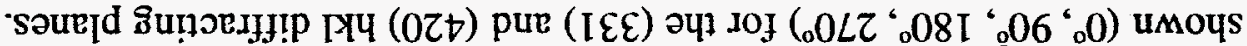

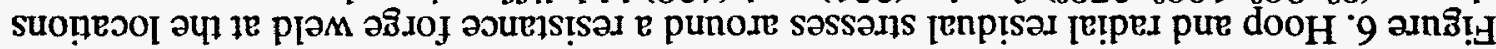

\begin{tabular}{|c|c|c|}
\hline $18-$ & $\forall 07-$ & $\overline{00 L z}$ \\
\hline$z_{t}-$ & $\forall \mathcal{E} \mathcal{E}-$ & .081 \\
\hline $861-$ & E9E - & .06 \\
\hline $82 \mathrm{I}-$ & $9 t \nabla=$ & 00 \\
\hline$(0 z t)$ & $(0 z p)$ & צread \\
\hline $\mathrm{I}=$ & $\mathrm{I17}-$ & $00 \angle 2$ \\
\hline 9EI- & $782-$ & $008 \mathrm{I}$ \\
\hline $681-$ & $792-$ & .06 \\
\hline $161-$ & $\angle S E-$ & 음 \\
\hline$(I \varepsilon \mathcal{E})$ & (IEE) & र्रroy \\
\hline $\begin{array}{l}\text { (EdW) } \\
\text { IEIDEY }\end{array}$ & $\begin{array}{l}\text { (EdW) } \\
\text { dooH }\end{array}$ & suonso \\
\hline
\end{tabular}

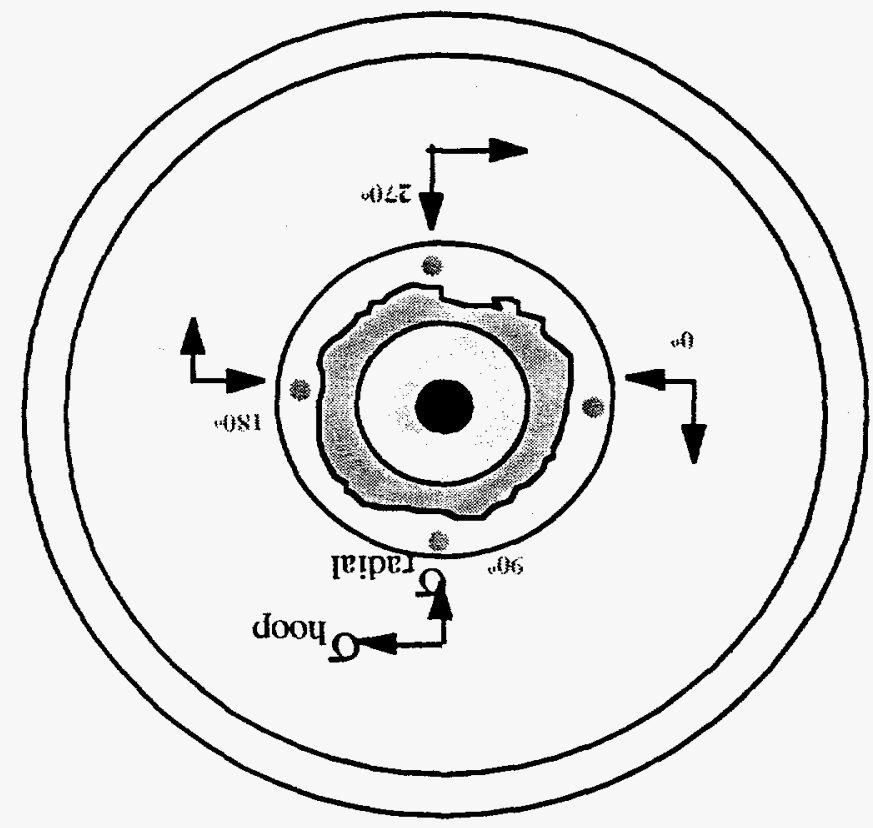

suopsas! [e!pey 8 doon

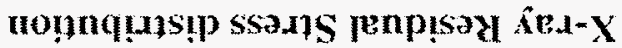
pais ss?u!uts o!nualsn 14!O! рәрРМ - SSGS 